\title{
Vitamin A Metabolism to Retinoic Acid and its Possible Implications in HIV/AIDS
}

\author{
Paul Kelly \\ Department of Medicine, University Teaching Hospital \\ Lusaka, Zambia
}

\section{INTRODUCTION}

In this review I endeavour to draw a picture of vitamin A biology which may be relevant to the way we use it in adults and children with HIV/AIDS. I will attempt to cover some basic science in this field and wish to draw attention to the serious deficiencies in the literature in our understanding of this biologically highly active vitamin. There is much scope for further research in this area. It is remarkable how a vitamin has been adopted as a central feature of prevention of childhood illness despite such significant gaps in our understanding. There is no question that vitamin $\mathrm{A}$ is beneficial for child health (this has been demonstrated in good randomised controlled trials), but how it works (in terms of immunology or epithelial biology), what happens to it after administration (metabolism), and whether the way we do things needs to be adjusted in HIV/AIDS are simply not known.

\section{The scientific and clinical basis for giving vitamin $A$}

Vitamin A is the term given to a collection of different but related molecules ${ }^{1}$. These include retinol, retinyl esters, retinoic acid (RA), and $\square$-carotene, most of which are interconvertible and can replace each other in the treatment of the vitamin A deficiency state. Vitamin A deficiency is clinically recognisable as night blindness, progressing to keratomalacia, and this is the only absolute indication for vitamin A treatment using high doses. However, vitamin A has also been shown to protect children from infectious disease, suggesting either that a borderline deficiency state exists which is associated with increased susceptibility to infectious disease, or that vitamin $\mathrm{A}$ has a pharmacological effect on the immune or other body systems, or both. Vitamin A supplementation programmes have now been implemented worldwide ${ }^{2}$, and in Zambia all children under 5 years are supposed to receive a mega-dose oral supplement every 6 months. There have been many studies which show an association between increased infectious disease and evidence of compromised vitamin A status, but these are confounded by the fact that serum retinol concentration, and probably bioavailability to tissues, are impaired during an acute phase response. The most reliable data therefore come from intervention studies. In Ghana, supplementation with retinol palmitate capsules (200,000i.u.) every 4 months was associated with a $34 \%(95 \% \mathrm{CI} 8 \%$ $53 \%$ ) reduction in deaths due to diarrhoeal disease in children under the age of 7.5 years and a reduction of $19 \%(95 \%$ CI $2 \%-32 \%)$ in all-cause mortality ${ }^{3}$. It is on the basis of this and other studies ${ }^{4}$ that vitamin A supplementation programmes, using intermittent treatment with mega-doses of retinol were widely adopted in the 1990s. Vitamin A supplements appear to have their greatest effects on treatment of measles and prevention of severe diarrhoea. There is little effect of vitamin A on mortality from respiratory infections $^{5}$ and supplementation may increase their incidence $^{6}$. However, in treatment of established diarrhoeal disease the benefit is much less certain. In general there appears to be little effect of vitamin A on acute diarrhoea ${ }^{7,89}$ except that due to Shigella ${ }^{10}$.

There is evidence that vitamin A supplementation in pregnancy reduces mortality ${ }^{11,12}$ Although high doses of vitamin A in early pregnancy can be teratogenic, regular lower doses to women in populations, such as in Nepal, where deficiency is prevalent seem to carry little risk ${ }^{13}$. The proximate teratogens appear to be the retinoic acids ${ }^{2}$, not retinol itself, and thus it is important to understand factors affecting retinol storage and metabolism to these active forms in 
individuals of differing health, vitamin A status and other physiological conditions.

In HIV infection, there is ample evidence of vitamin A deficiency. Most vitamin A supplementation trials have been in HIV-infected pregnant or lactating women with the primary aim to decrease mother-tochild transmission. Although transmission appears unaffected by vitamin A supplements, there is evidence that vitamin A has benefits for morbidity and mortality in HIV-infected children, a group particularly at risk for deficiency ${ }^{14,15}$. One randomised trial which included vitamin A as part of a multiple micronutrient supplement did show a significant reduction in mortality of Thai adults ${ }^{16}$. However, morbidity was not reduced, nor was CD4 count improved, so the mechanism of benefit was not clear. A recent trial conducted in Lusaka showed some early evidence of reduced mortality in HIV-infected adults, but the numbers of deaths were small as the trial was not powered to analyse a mortality effect ${ }^{17}$.

A recent report from Tanzania has raised concerns about the safety of retinol in HIV-infected adults ${ }^{18}$. A randomised controlled trial was conducted in 1078 pregnant HIV-infected women, and in a factorial design two interventions were tested against placebo individually and in combination: vitamin $\mathrm{A}$ was compared against vitamins B, C and E. The B,C,Etreated women showed a modest reduction in progression, increased CD4 count, and reduced viral load, but this effect was blunted when given in combination with vitamin A. The study showed no effect on diarrhoeal disease, but respiratory infections were reduced by $21 \%(p=0.02)$ in women given vitamins B,C, and E. In another study from Zimbabwe, vitamin A supplementation of HIVinfected children reduced mortality by $28 \%$ $(\mathrm{P}=0.01)$, but mortality was doubled in HIV-negative children born to HIV-infected mothers ${ }^{19}$.

It is clear that vitamin A supplementation is usually beneficial, but this depends on the population under study, and differences in dose and formulation between trials may also determine whether benefit is seen. There is no consensus on the conditions under which benefit is likely to be seen. It is my belief that these apparent contradictions will not be resolved until more is know about the metabolism of vitamin A under different circumstances.

\section{The metabolism of vitamin $A$}

Vitamin A is present in the diet either as retinyl esters (with fatty acids, usually in the all-trans isomeric configuration) or as plant precursors of which the greatest share is $\square$-carotene which comprises two retinol molecules. Retinyl esters are hydrolysed in the intestinal lumen or in the enterocyte and retinol is then taken up against its concentration gradient by complexing with cellular retinol binding proteins (cRBP)-I and II in the enterocyte ${ }^{20}$. cRBP-II is upregulated by dietary fatty acids $^{21}$, which, in addition to the stimulation of bile release by dietary fat, may explain why some observers have found vitamin A absorption to be enhanced when coadministered with fat. cRBP-1 also functions to promote retinol esterification, and cRBP-I null mice exhibit increased synthesis of RA through the action of $\mathrm{ADH}$. Carotenoids are hydrolysed in the enterocyte to retinol, retinal or apocarotenoids. There is also evidence that all-trans-retinoic acid (ATRA) can be produced directly from $\square$-carotene by excentric cleavage ${ }^{22}$, although this is controversial. Retinal is reduced to retinol. Retinol is then reesterified and exported as chylomicrons, which are absorbed in the liver and retinyl esters are stored in stellate cells. All-trans retinol is transported from the liver to peripheral tissues complexed to retinol binding protein (RBP), in holo-RBP, and transthyretin. Holo-RBP is recognised by specific receptors and retinol taken up across the plasma membrane. The remaining particle, apo-RBP, is degraded in the kidney.

In the enterocyte a proportion of retinol is oxidised to retinoic acid. The proportion which goes down this pathway is uncertain, and there are few data on factors which determine this proportion. More is known about hepatic interconversion of these forms under enzymatic control ${ }^{23}$ :

RE $\underset{\text { LRAT }}{\stackrel{\mathrm{REH}}{\longrightarrow}}$ Retinol $\underset{\mathrm{AR}}{\stackrel{\mathrm{ADH}}{\rightleftarrows}}$ Retinal $\stackrel{\mathrm{RDH}}{\longrightarrow}$ Retinoic acid $\stackrel{\mathrm{CYP} 26}{\longrightarrow}$ RA metabolites

Lecithin: retinol acyl transferase (LRAT) catalyses the esterification of retinol for storage. Retinyl ester hydrolase $(\mathrm{REH})$ reverses this reaction. $\mathrm{ADH}$ is alcohol dehydrogenase, but only medium- and shortchain enzymes perform the oxidation of retinol, and 
$\mathrm{RDH}$ is retinal dehydrogenase. Alcohol competes for $\mathrm{ADH}$, so retinoic acid metabolism is altered in alcohol dependent adults ${ }^{24}$. AR is aldose reductase. CYP26 is a member of the cytochrome P450 system which converts ATRA into hydroxy-, keto-, and glucuronyl- metabolites which have reduced bioactivity and may represent an excretion pathway, e.g. in bile. The interactions within this system have been elucidated by work in rats. In VAD, LRAT is virtually inactive, but rapidly induced by feeding with retinol, and this is mediated by ATRA through RAR (the retinoic acid receptor, see below). This effect does not operate in intestine, just in liver. In health, RA appears to signal repletion of body stores of vitamin A, and this leads to reduced export of retinol through holo-RBP ${ }^{23}$. CYP26 is inducible by ATRA due to the presence of a retinoic acid response element (RARE) in its promoter (see below). Again, its activity in vitamin A deficiency is negligible, but the induction of CYP26 by RA is also observed in small intestine ${ }^{25}$. This system suggests that there is negative feedback by which RA concentration is regulated.

Small intestinal enterocyte cytosolic fractions can oxidise retinol directly to ATRA $^{26}$, which may explain why the concentration of ATRA in porcine portal and systemic venous blood is higher following administration of high dose retinol than after administration of a meal of liver containing the same dose of retinol ${ }^{27}$. A similar effect has been shown in peripheral blood in humans ${ }^{28}$. There are no data to our knowledge regarding the impact of vitamin A supplements on these metabolic pathways.

\section{Molecular effects of vitamin $A$}

The importance of retinol at a molecular level appears to be largely through retinoic acid (RA), one of the most powerful transcriptional regulators known. There are three major isoforms of retinoic acid, 9-cis RA, 13-cis RA, and all-trans retinoic acid (ATRA), apart from 11-cisRA which is only required as the substrate for the synthesis of rhodopsin in the retina. These retinoids bind to specific receptors in the nucleus and the receptor-ligand complex then acts as a transcription factor in the classical sense by binding to specific DNA sequences (RAREs) in open chromatin. The receptors to which retinoic acid binds are members of the steroid-thyroid hormone receptor superfamily, which are examples of multi-cysteine zinc finger transcription factors and require zinc for their molecular conformation. There are two protein receptors which participate in recognition of retinoic acid isoforms, termed RAR and RXR, and they form homo-dimers or hetero-dimers. It is the pairing of these receptor dimers which confers ligand specificity on the receptor complex and determines the response element in gene promoter sequences to which they will bind. The three isoforms of each of RAR and RXR, $\square, \square$ and $\square$, have different tissue expression specificities. Thus, the RXR-RXR homodimer binds 9-cisRA and recognises the RXRE response element sequence AGGTCANAGGTCA. The RXR-RAR heterodimer binds ATRA and recognises the RARE response elements A G G T C A N N A G G T C A O r AGGTCANNNNNAGGTCA. These response elements are composed of two repeats of the consensus motifAGGTCA, and it is only the spacing between these sequences which differs.

Importantly, it is retinoic acid which is the transcriptionally active retinoid, and therefore an understanding of the factors which determine oxidation of retinol to the isoforms of RA is critical to understanding the biological consequences of vitamin A administration.

\section{Physiological effects of vitamin A on immune cells}

This subject has recently been reviewed and it is clear that available data are few $^{29}$. Vitamin A deficient children in Indonesia had lower CD4/CD8 ratios, lower proportions of CD4 naïve T cells, and higher proportions of $\mathrm{CD} 8, \mathrm{CD} 45 \mathrm{RO} \mathrm{T}$ cells than nonvitamin A deficient children, and these abnormalities were all reversed after treatment with $60 \mathrm{mg}$ retino $^{30}$.

For many years immunologists have used the terms 'Th1' and 'Th2' to explain some observations about the cytokine expression profile of T cells. In brief, Th1 cells secrete pro-inflammatory cytokines such as interleukin (IL)-2 and interferon (IFN)- $\square$, under the control of other cytokines such as MIF, IL-12 and IL-18, and they direct a cell-mediated immune response to viral and other intracellular infections, often leading to the release of TNF- $\square$. Th2 cells secrete IL-4, IL-5 and IL-10, under the control of IL- 
4, IL-10 and IL-13 and direct an antibody-mediated immune response to extracellular pathogens. Th1 and Th2 cells down-regulate each other. Recently, certain transcription factors have been recognised to be highly discriminating differentiation markers of these T cell subsets: T-bet is a Th1 marker and GATA3 is a Th2 marker. A third subset of regulatory T cells (Th0 or ThR) has been described; these secrete the potent anti-inflammatory cytokines TGF- $\square$ and IL10.

Vitamin A deficiency (VAD) compromises antibody responses in rats to $\mathrm{T}$ cell dependent antigens such as tetanus toxoid. Rats immunised during vitamin A deficiency can generate normal $\operatorname{IgG}$ and $\operatorname{IgM}$ responses following rescue with retinol or ATRA, indicating that memory cell formation is not the defect $^{31}$, although recent work with an adoptive transfer model in mice contradicts this. Retinoic acid is known to enhance $\mathrm{T}$ cell activation by mitogens, and augmented antibody production by $\mathrm{B}$ cells ${ }^{31}$. The key Th1 cytokine interferon (IFN)- $\square$ binds to its receptor and ultimately activates STAT-1 by phosphorylation, which then translocates to the nucleus of the cell and binds as homo- or heterodimers to the promoter regions of IFN- $\square$ responsive genes. ATRA can amplify this response by binding to an RA response element (RARE) in the promoter of the STAT-1 gene ${ }^{32}$.

On the other hand, retinoids inhibit B cell proliferation in response to direct stimulation with anti-IgM antibodies, and this was shown to be mediated through RAR $\square$ and RAR $\square$, not through $\mathrm{RXRs}^{33}$. Simultaneously, apoptosis was also inhibited, so B cells in this model system were rendered long-living but quiescent.

$\mathrm{NF}-\square \mathrm{B}$ is a critical intracellular signalling point for pro-inflammatory cytokines, and it is also a key component of signal transduction pathways for the innate pattern recognition receptors Toll-Like Receptors (TLRs). Using a whole-body imaging method in mice, VAD was shown to lead to elevation of whole-body NF- $\square$ B activation. This effect was reversed by ATRA and reproduced by administration of the RAR-pan antagonist AGN194310 ${ }^{34}$. ATRA has been shown to induce transcription of the cathelicidin gene PR-39 in bone marrow cells ${ }^{35}$ and induces $\square$-defensin gene expression in human myeloid cells ${ }^{36,37}$.
There has been very little work on gut lymphoid cells. In one study, in colonic lymphocytes recovered from resection specimens, retinol suppressed and ATRA enhanced lymphocyte proliferation as measure by thymidine incorporation, and ornithine decarboxylase activity (the first step in polyamine synthesis) was also increased $^{38}$.

The single most important cytokine required for the down-regulation of inflammatory responses is TGF$\square$, secreted by regulatory $\mathrm{T}$ cells. In VAD rats, expression of TGF- $\square 2$ was reduced in intestinal mucosa, but this effect was reversible by RA administration $^{39}$. We have recently undertaken a systematic search for retinoid response elements (RARE and RXRE) in the 5'-untranslated regions of key immunological genes (unpublished data). We found the RAR orphan receptor (i.e. half the receptor dimer binding site) response element in the 5'-UTRs of TGF- $\square$ 1, TGF- $\square$ receptor-1 (which incidentally both also contain a metal response element which would respond to zinc), IL-1 receptor-2, and IL-10. There are multiple RAREs in the TGF- $\square$ R1 5'-UTR, which is of great interest in view of the central role of TGF- $\square$ in down-regulating pro-inflammatory cytokine responses.

\section{Physiological effects of vitamin A on intestinal cells}

Vitamin A has direct effects on the intestinal mucosa. In animal models, intestinal adaptation is reduced in vitamin A deficiency, and this effect is mediated over 48 hours by reduced cell proliferation and migration and increased apoptosis ${ }^{40}$. Vitamin A deficiency in rats leads to reduced number of goblet cells and reduced glycoprotein synthesis ${ }^{41}$.

In children with increased intestinal permeability due to tropical enteropathy, vitamin A (16,700i.u. weekly for 8 weeks) given to children attending a clinic with minor ailments significantly reduced intestinal permeability, and 200,000i.u. single dose given to children with increased permeability due to diarrhoea significantly enhanced the rate of reduction in permeability ${ }^{42}$. In another study, vitamin A improved gastrointestinal integrity in children ${ }^{43}$.

Retinoids also induce expression of genes involved in retinoid signalling and vitamin A transport across the intestinal mucosa. Retinol and ATRA induced 
RAR $\square$ and cRBP-I in fetal and Caco 2 cells, but neither retinoid induced epithelial cell differentiation $^{44}$. Both ATRA and 9-cisRA induced expression of cRBP-II in Caco-2 cells and this was associated with a $50 \%$ increase in retinol uptake by the cells ${ }^{45}$. Again, RAR $\square$ was also induced. In humans, the RA effect on cRBP-II must be indirect as the 5'-untranslated region has no RXR binding site ${ }^{46}$. There is also a specific transcriptional effect of RA on the apical sodium-dependent bile acid transporter in humans, which is up-regulated 4-fold by ATRA but down-regulated by bile acids themselves ${ }^{47}$.

\section{Vitamin A and HIV/AIDS in Zambia}

In a community survey in Ndola, northern Zambia, the prevalence of hyporetinolaemia in unselected adults was $20 \%$, and this was increased in HIV infection and $\operatorname{AIDS}^{48}$. Since the introduction of vitamin A fortification of sugar this proportion is likely to have fallen. However, in patients with advanced AIDS in the University Teaching Hospital, Lusaka, in collaboration with Dr Kafwembe in TDRC, we observed that serum concentrations of retinol did not respond with the same rise after a mega-dose of retinol as in HIV seronegative controls $^{49}$, and there may be a malabsorption problem. In a recent trial, the effects even of multiple micronutrient supplementation were modest, though we did find some interesting evidence of reduced mortality as noted above ${ }^{17}$. More work needs to be done. We are currently examining the impact of multiple micronutrient supplements on vaccine responsiveness, which is another field in which much remains to be learned.

It seems to me that despite much theoretical knowledge on the basic biology of vitamin A and retinoic acids, there is much we do not know and which we need to find out if we are to resolve the fundamental uncertainties in the results of the two clinical trials ${ }^{18,19}$ which have generated these worrying data on mortality. There is no immediate cause for concern there is a great deal of evidence that vitamin A does a lot of good, and these trials were few in number and not primarily directed at looking at these effects. But we do need more research on micronutrients in general and vitamin A in particular to see how we can best use these very potent molecules for the benefit of our patients.

\section{REFERENCES}

1. Gibson RS. Principles of nutritional assessment. Oxford: Oxford University Press, 2005. pp478481.

2. Micronutrient Initiative Progress in controlling vitamin A deficiency. Micronutrient Initiative, Ottawa 1998.

3. Ghana VAST Study Team. Vitamin A supplementation in Northern Ghana. Effects on clinic attendances, hospital admissions and child mortality Lancet 1994; 344: 228-231.

4. Beaton, G.H., Martorell, R., Aronson, K.J, (1993) Effectiveness of vitamin A supplementation in control of young child morbidity and mortality in developing countries. State of the Art Series Nutrition Policy Discussion paper No 13. United Nations Administrative Committee on Coordination / subcommittee in Nutrition, 1993.

5 Vitamin A and Pneumonia Working Group, Bull WHO 73: 609, 1995

6 Grotto I, Mimouni M, Gdalevich M, Mimouni D. Vitamin A supplementation and childhood morbidity from diarrhoea and respiratory infections: a meta-analysis. J Pediatr 2003; 142: 297-304.

7 Henning B, Stewart K, Zaman K, Alam AN, Borwn KH, Black RE. Lack of therapeutic efficacy of vitamin A for non-cholera, watery diarrhoea in Bangladeshi children. Eur J Clin Nutr 1992; 46: 437-443.

8 Dewan V, Patwari AK, Jain M, Dewan. A randomised controlled trial of vitamin A supplementation in acute diarrhoea. Indian Pediatr 1995; 32:21-25.

9 Faruque ASG, Mahalanabis D, Haque SS, Fuchs GJ, Habte D. Double-blind randomized controlled trial of zinc or vitamin A supplementation in young children with acute diarrhoea. Acta Paediatr 1999: 88: 154-60.

10 Hossain S, Biswas R, Kabir I, Sarker S, Dibley M, Fuchs G, Mahalanabis D. Single dose vitamin A treatment in Bangladeshi children: randomised double blind controlled trial. BMJ 1998; 316: 422-6.

11 West K, Katz J, Khatry SK, LeClerq SC, Pradhan EK, Shrestha SR, Connor PB, Dali SM, Christian P, Pokhrel RP, Sommer A. Double blind, cluster randomised trial of low dose 
supplementation with vitamin A or $\square$-carotene on mortality related to pregnancy in Nepal. BMJ 1999; 318: 570-5.

12 Christian P, West KP, Khatry SK, katz J, LeClerq SC, Pradhan EK, Dali SM, Shrestha SR. Vitamin or $\square$-carotene supplementation reduces symptoms of illness in pregnant and lactating Nepali women. J Nutr 2000; 130: 2675-82.

13 World Health Organization, Micronutrient Initiative. Safe vitamin A dosage during pregnancy and lactation. WHO/MI, 1998.

14 Coutsoudis A, Bobat RA, Coovadia HM, Kuhn L, Tsai WY, Stein ZA. The effects of vitamin A supplementation on the morbidity of children born to HIV-infected women. Am J Pub Health 1995; 85: 1076-81.

15 Fawzi WW, Mbise RL, Hertzmark E, Fataki MR, Herrera MG, Ndossi G, Spiegelman D. A randomised trial of vitamin A supplements in relation to mortality among human immunodeficiency virus-infected and uninfected children in Tanzania. Pediatr Infect Dis J 1999; 18: 127-33.

16 Jiamton S, Pepin J, Suttent R, Filteau S, Mahakkanukrauh B, Hanshaoworakul W, Chaisilwattana P, Suthipinittharm P, Shetty P, Jaffar $S$. A randomized trial of the impact of multiple micronutrient supplementation on mortality among HIV-infected individuals living in Bangkok. AIDS 2003; 17: 2461-2469.

17 Kelly P, Katubulushi M, Todd J, Banda R, Yambayamba V, Fwoloshi M, Zulu I, Kafwembe E, Yavwa F, Sanderson IR, Tomkins A. Micronutrient supplementation has a limited effect on intestinal infectious disease and mortality in a Zambian population of mixed HIV status: a cluster randomized trial. Am JClin Nutr 2008; 88: 1010-1017.

18 Fawzi WW, Msamanga GI, Spiegelman D, Wei R, Kapiga S, Villamor E, Mwakagile D, Mugusi F, Hertzmark E, Essex M, Hunter D. A randomized trial of multivitamin supplements and HIV disease progression and mortality. New Engl J Med 2004; 351: 20-29.

19 Humphrey JH, Illiff P, Marinda ET et al. Effects of a single large dose of Vitamin A, given during the postpartum period to HIV-positive women and their infants, on child HIV infection, HIVfree survival, and mortality. J Infect Dis 2006; 193: 860-871.

20 Xueping E, Zhang L, Lu J, Tso P, Blaner W,
Levin MS. Increased neonatal mortality in mice lacking cellular retinol-binding protein II. J Biol Chem 2002; 277: 36617-36623.

21 Takase S, Suruga K, Goda T. Regulation of vitamin A metabolism-related gene expression. Br J Nutr 2000; 84: S217-221.

22 Hebuterne X, Wang XD, Smith DE, Tang G, Russell RM. In vivo biosynthesis of retinoic acid from $\square$-carotene involves an excentric cleavage pathway in ferret intestine. J Lipid Res 1996; 37: 482-492.

23 Ross AC. Retinoid production and catabolism: role of diet in regulating retinol esterification and retinoic acid oxidation. J Nutr 2003; 133: 291S-296S.

24 Crabb DW et al. Alcohol and retinoids. Alcoholism: clinical and experimental research 2001; 25:207S-217S.

25 Wang Y, Zolfaghari R, Ross AC. Cloning of rat cytochrome P450RAI (CYP26) mRNA and regulation of its gene expression by all-trans retinoic acid in vivo. Arch Biochem Biophys 2002; 401:235-243.

26 Lampen A, Meyer S, Arnhold T, Nau H. Metabolism of vitamin A and its active metabolite all-trans retinoic acid in small intestinal enterocytes. J Pharm Exp Therap 2000; 295: 979-985.

27 Arnhold T, Nau H, Meyer S, Rothkoetter HJ, Lampen AD. Porcine intestinal metabolism of excess vitamin A differs following vitamin A supplementation and liver consumption. J Nutr 202; 132: 197-203.

28 Buss NE, Tembe EA, Prendergast BD, Renwick AG, George CF. The teratogenic metabolites of vitamin A in women following supplements and liver. Hum Exp Toxicology 1994; 13: 33-43.

29 Villamor E, Fawzi WW. Effects of vitamin A supplementation on immune responses and correlation with clinical outcomes. Clin Microbiol Rev 2005; 18: 446-464.

30 Semba RD, Muhilal, Ward BJ, Griffin DE, Scott AL, Natadisastra G, West KP, Sommer A. Abnormal T cell subset proportions in vitamin A deficient children. Lancet 1993; 341: 5-8.

31 DeCicco KL, Ross AC. All-trans retinoic acid and PIC cooperate to elevate anti-tetanus IgG and IgM responses in vitamin A-deficient Lewis rats and BALB/c mice. Proc Nutr Soc 2000; 59: 519-529.

32 Darnell JE, Kerr IM, Stark GR. Jak-STAT 
pathways and transcriptional activation in response to interferons and other extracellular signaling proteins. Science 1994; 264: 14151420.

33 Lomo J, Smeland EB, Ulven S, Natarajan V, Blomhoff R, Gandhi U, Dawson MI, Blomhoff HK. RAR- not RXR- ligands inhibit cell activation and prevent apoptosis in Blymphocytes. Cell Physiol 1998; 175: 68-77.

34 Austenaa LMI, Carlsen H, Ertesvag A, Alexander G, Blomhoff HK, Blomhoff R. Vitamin A status significantly alters $N F-\kappa B$ activity assessed by in vivo imaging. FASEB J 2004; 18: 1255-1257.

$35 \mathrm{Wu} \mathrm{H}$, Zhang G, Minton E, Ross CR, Blecha F. Regulation of cathelicidin gene expression: induction by lipopolysaccharide, interleukin-6, retinoic acid and Salmonella typhimurium serovar typhimurium infection. Infect Immun 2000; 68: 5552-5558.

36 Herwig S, Su Q, Zhang W, Ma Y, Tempst P. Distinct temporal patterns of defensin mRNA regulation during drug-induced differentiation of human myeloid leukemia cells. Blood 1996; 87:350-364.

37 Wang N, Su Q, Boeckh-Herwig S, Yaneva M, Tempst P. Delayed-late activation of a myeloid defensin minimal promoter by retinoids and inflammatory mediators. Leukemia Res 2004; 28; 879-889.

38 Elitsur Y, Neace C, Liu X, Dosescu J, Moshier JA. Vitamin A and retinoic acid immunomodulation of human gut lymphocytes. Immunopharmacology 1997; 35: 247-253.

39 Glick AB, McCune BK, Abdulkarem N, Flanders KC, Lumadue JA, Smith JM, Sporn MB. Complex regulation of TGF- $\kappa$ expression by retinoic acid in the vitamin A-deficient rat. Development 1991; 111: 1081-1086.

40 Swartz-Basile DA, Wang L, Tang Y, Pitt HA, Rubin DC, Levin MS. Vitamin A deficiency inhibits intestinal adaptation by modulating apoptosis, proliferation, and enterocyte migration. Am J Physiol Gastrointest Liver Physiol 2003; 285: G424-432.
41 Olson JA, Rojanapo W, Lamb AJ. The effect of vitamin A status on the differentiation and function of goblet cells in the rat intestine. Ann NYAcad Sci 1981; 359: 181-191.

42 ThurnhamDI, Northrop-Clewes CA, McCullough FSW, Das BS, LunnPG. Innate immunity, gut integrity, and vitamin $\mathrm{A}$ in Gambian and Indian infants. J Infect Dis 2000; 182: S23-28.

43 Filteau SM, Rollins NC, Coutsoudis A, Sullivan KR, Willumsen JF, Tomkins AM. The effect of antenatal vitamin $A$ and $\kappa$-carotene supplementation on gut integrity of infants of HIV-infected South African women. J Pediatr Gastro Nutr 2001; 32: 464-470.

44 Plateroti M, Sambuy Y, Nobili F, Bises G, Perozzi G. Expression of epithelial markers and retinoid-binding proteins in retinol- or retinoic acid-treated intestinal cells in vitro. Exp Cell Res 1993; 208: 137-147.

45 Levin MS, Davis AE. Retinoic acid increases cRBP-II mRNA and retinol uptake in the human intestinal Caco-2 cell line. J Nutr 1997; 127: 1317.

46 Zhang L, Xueping E, Luker KE, Shao J-S, Levin MS, Suh E, Li E. Analysis of human cRBP-II promoter during enterocyte differentiation. Am J Physiol Gastrointest Liver Physiol 2002; 282: G1079-1087.

47 Neimark E, Chen F, Li X, Shneider BL. Bile acidinduced negative feedback regulation of the human ileal bile acid transporter. Hepatology 2004; 40: 149-156.

48 Kafwembe E, Kelly P, Ngalande P. Vitamin A in HIV infection and AIDS. E Afr Med $J$ 2001; 78: 451-453.

49 Kelly P, Musuku J, Kafwembe E, Libby G, Zulu I, Murphy J, Farthing MJG. Impaired bioavailability of vitamin $\mathrm{A}$ in adults and children with persistent diarrhoea in Zambia. Aliment Pharmacol Therap 2001; 15: 973-979. 